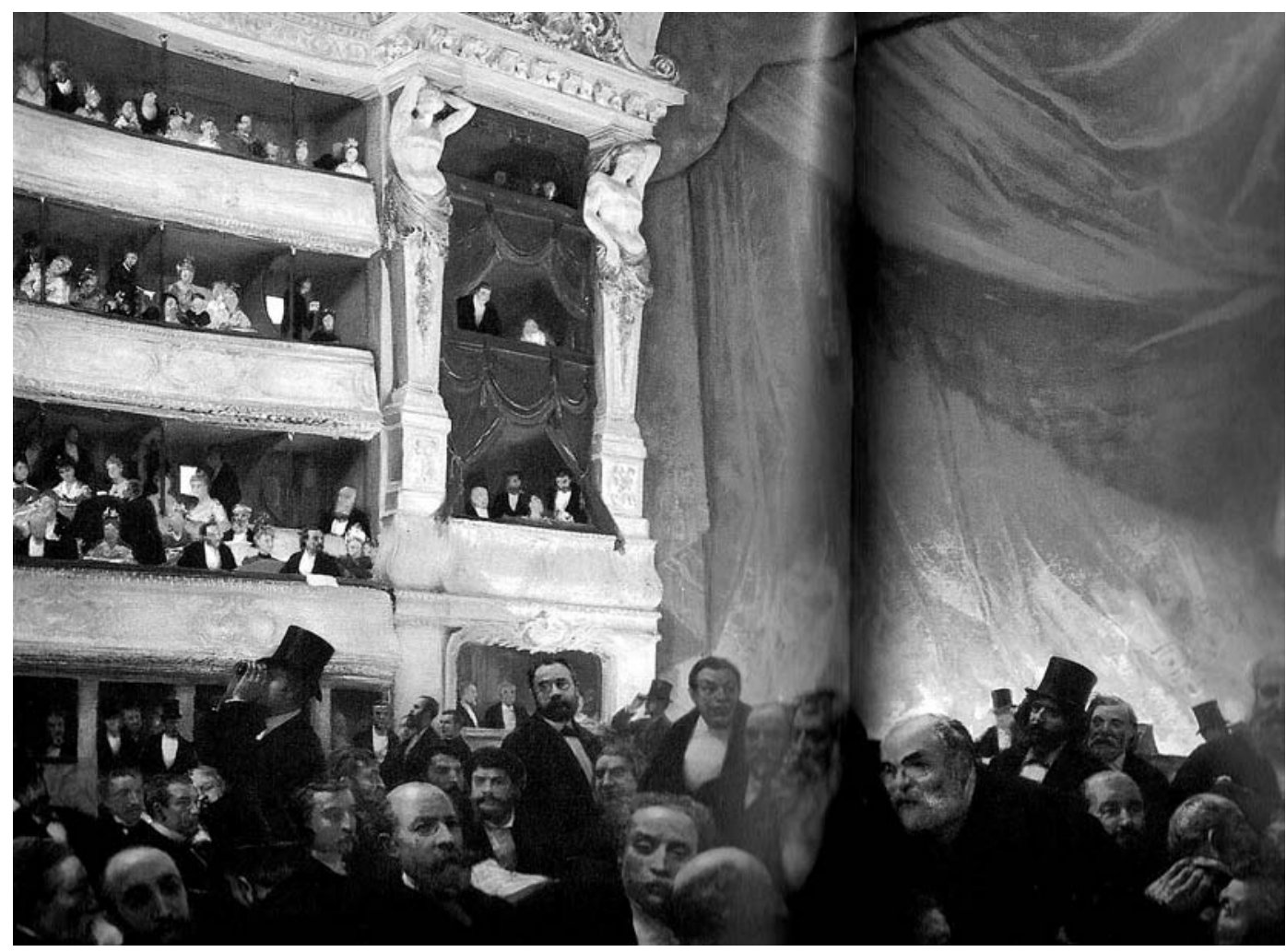

\title{
A descentralização e a organização do teatro em França Breve panorâmica
}

\author{
Jean-Pierre Wurtz ${ }^{1}$
}

\section{A história em poucas palavras}

A partir de meados do século XIX a vida teatral francesa oscila entre os dois pólos do divertimento e da vontade educadora. 0 Segundo Império assiste à expansão do teatro de boulevard, de vaudeville e outras paródias, farsas jocosas, revistas ligeiras e operetas, dignas flores do que se convencionou chamar "a vida parisiense".

As coisas vão tomar outro rumo na altura da Comuna de Paris. Durante as dez semanas deste periodo insurreccional e revolucionário (19 de Março - 27 de Maio de 1871), a vida teatral é sem dúvida das mais reduzidas. Ao lado da Comédie Française funciona uma dúzia de salas que continuam essencialmente a limitar-se, como se nada se passasse, ao boulevard e ao vaudeville.

Perante esta frivolidade, ciente da dimensão fortemente social da actividade teatral, e tendo por objectivo a educação da população, a Comuna, referindo-se a um decreto revolucionário da Convenção (12 germinaf ano $\|-1^{\circ}$ de Abril de 1794), decreta, no dia 12 de Maio de 1871, que "os teatros têm por objectivo o ensino", julgando com Edouard Vaillant que "os teatros devem ser considerados sobretudo como uma grande instituição de instrução [e que] numa república não devem ser senão isso".

Aprovado no próprio dia da entrada das tropas de
Versalhes em Paris, e oito dias antes do trágico fim da Comuna, este decreto acabou por não ter aplicação imediata. Todavia, é interessante reparar que, em plena efervescência revolucionária, a Comuna de Paris teve a preocupação de lançar as premissas de uma política teatral.

É igualmente verosimil que, no final do século, esta convicção "pedagógica" tenha inspirado movimentos de educação popular, pela implementação, na província, de iniciativas como o Teatro do Povo de Bussang, nos Vosgos, fundado em 1895 e ainda em actividade, e a das universidades populares parisienses pelo seu apoio aos teatros de bairro. É nesta preocupação ao mesmo tempo estética e ética, artística e cívica, que se baseia, no início do século XX, a acção dos precursores da descentralização dramática, entre eles Firmin Gémier e Jacques Copeau, e mais tarde, na segunda metade do século, a

descentralização propriamente dita, tendo como figura emblemática Jean Vilar.

Firmin Gémier, nascido em 1869 em Aubervilliers, imagina, em 1911, um efémero "Teatro nacional itinerante", antes de fundar, em 1920, o Théâtre National Populaire, que trinta anos mais tarde se tornaria no famoso TNP de Jean Vilar. 0 projecto de Gémier mantém, nos seus princípios, toda a sua actualidade, na medida em que:
1 Inspector-geral do teatro em França.

Calendário republicano francês. 
abria para uma nova função social do teatro; visava a procura de novos públicos; colocava a difícil e necessária equação da relação entre o teatro e, ao mesmo tempo, a procura do público popular e a criação do seu tempo; abordava a questão da responsabilidade do Estado no campo do teatro.

Como contraponto e complemento desta abordagem, Jacques Copeau, nascido em Paris em 1879, contemporâneo de Gémier, é por sua vez o apóstolo de uma festa teatral mais intima, mais rigorosa, mais exigente artisticamente, o apóstolo do teatro para partilhar como o pão, onde quer que fosse, no seu teatro parisiense do Vieux Colombier ou na praia de uma aldeia. Em 1924, depois de ter fundado, e a seguir dirigido ao longo de uma década, o teatro do Vieux Colombier, também Copeau cai na tentação de um "retorno às fontes do teatro popular". 0 encenador fecha o seu teatro parisiense e lança-se, nos arredores da Borgonha, na perseguição desesperada do seu sonho juntamente com cerca de trinta alunos. Eles representam - nas praças públicas, nas cidades e nas aldeias - farsas do seu repertório e um espectáculo colectivo que celebrava a vindima e o vinho. Esta "redenção teatral" tem a duração de cinco anos: Copeau interrompe-a bruscamente em 1929

Estas aventuras individuais são em breve assumidas oficialmente pelos poderes públicos. É na altura da Frente Popular, em 1936, que o Estado pensa pela primeira vez em lançar as bases duma política teatral. A pedido do governo, Charles Dullin redige e entrega em Setembro de 1938 um relatório que concluía sobre a urgência de uma descentralização em matéria teatral. Denuncia a hipertrofia artística da capital e defende com paixão a organização da França em regiões "bastante vastas para não fazerem uma arte de campanário" e a criação de "prefeituras artísticas" que, animadas em estilos diferentes (análogos aos vários estilos da Renascença italiana) por homens de teatro experientes, alimentariam "os cantos mais remotos". Paralelamente, no dia 14 de Janeiro de 1939, é votada a lei que institui a Reunião dos teatros de ópera nacionais e que prevê também "um esforço considerável em prol dos teatros de província".

A guerra irá interromper o processo em curso e será necessário esperar a Libertação para que estas ideias comecem a ser realizadas. É, portanto, um movimento de cerca de cinquenta anos, que defende - desde o início e até este momento - um princípio constante, que ultrapassa todas as vicissitudes políticas, ou seja, uma forte participação do Estado e, progressivamente, do conjunto dos poderes regionais no apoio à vida teatral, bem como a fiel solidariedade entre o teatro e a República, entre a República e os seus artistas, visando um duplo objectivo: de um ponto de vista geográfico, estimular a implementação de instituições dramáticas e culturais nas regiões e nos arredores parisienses, num espirito de desenvolvimento cultural do território; de um ponto de vista social, favorecer a procura de novos públicos, que poderiam ser definidos como "populares". A estas duas linhas de força acrescentar-se- á uma terceira: o questionamento da frivolidade que foi durante muito tempo aceite na vida teatral (no vaudeville, no teatro de boulevard) em beneficio duma atitude artisticamente mais exigente, mais preocupada com a função social da arte, e apoiando-se principalmente, ao lado dos clássicos, na criação e nos autores contemporâneos. É este o movimento geralmente designado pela expressão "descentralização dramática".

\section{Algumas datas fundadoras}

Nos anos seguintes à Libertação, a grande artífice da descentralização dramática é Jeanne Laurent, vice-directora dos espectáculos e da música junto da Direcção Geral das Artes e das Letras de 1946 a 1952.

Em 1946, ela cria, na Alsácia, o primeiro centro dramático nacional (o Centre Dramatique de l'Est) e, no ano seguinte, Jean Vilar cria o Festival de Avigon. Em 1951, Jeanne Laurent nomeia Jean Vilar para chefiar o Théâtre National Populaire (TNP) renovado, favorecendo assim, por doze anos, a expansão da dupla aventura vilariana do TNT e do Festival de Avignon.

Em 1959, é criado o primeiro Ministério dos Assuntos Culturais, atribuido a André Malraux. Em 1961, abre-se, no Havre, a primeira Maison de la Culture, logo seguida pela de Bourges, em 1962. Criadas por iniciativa de Malraux, estas " Casas" são as primeiras malhas de uma ambiciosa rede nacional de instituições culturais multidisciplinares, co-financiadas em partes iguais pelo Estado e pelos poderes regionais, constituindo um símbolo de empenhamento conjunto das instituições públicas no que diz respeito às artes do espectáculo, e em especial ao teatro.

A partir de 1977 são progressivamente criadas, na totalidade do território nacional, as Direcções Regionais dos Assuntos Culturais (DRAC), que não são organismos do poder regional, mas representantes do Estado, concretamente do Ministério da Cultura, a nível regional. 0 director é assessorado por uma equipa de conselheiros, entre os quais figura um pelo sector do teatro.

Em 1998 são reunidas as direcções que até essa altura estavam ligadas de um lado ao teatro e aos espectáculos, do outro lado à música e à dança, no âmbito de uma direcção única "da música, da dança, do teatro e dos espectáculos".

\section{Breves apontamentos sobre a organização do teatro, hoje}

A vida teatral profissional está hoje organizada nos seguintes grandes sectores:

- Três grandes redes institucionais públicas: os teatros nacionais (5), os centros dramáticos (40) e as cenas nacionais (70);

- Um importante fervilhar de "companhias independentes", de espaços, de organismos especializados e de festivais, incluindo um número considerável de companhias de espectáculos de rua ("artes de rua") e de "novo circo"; 

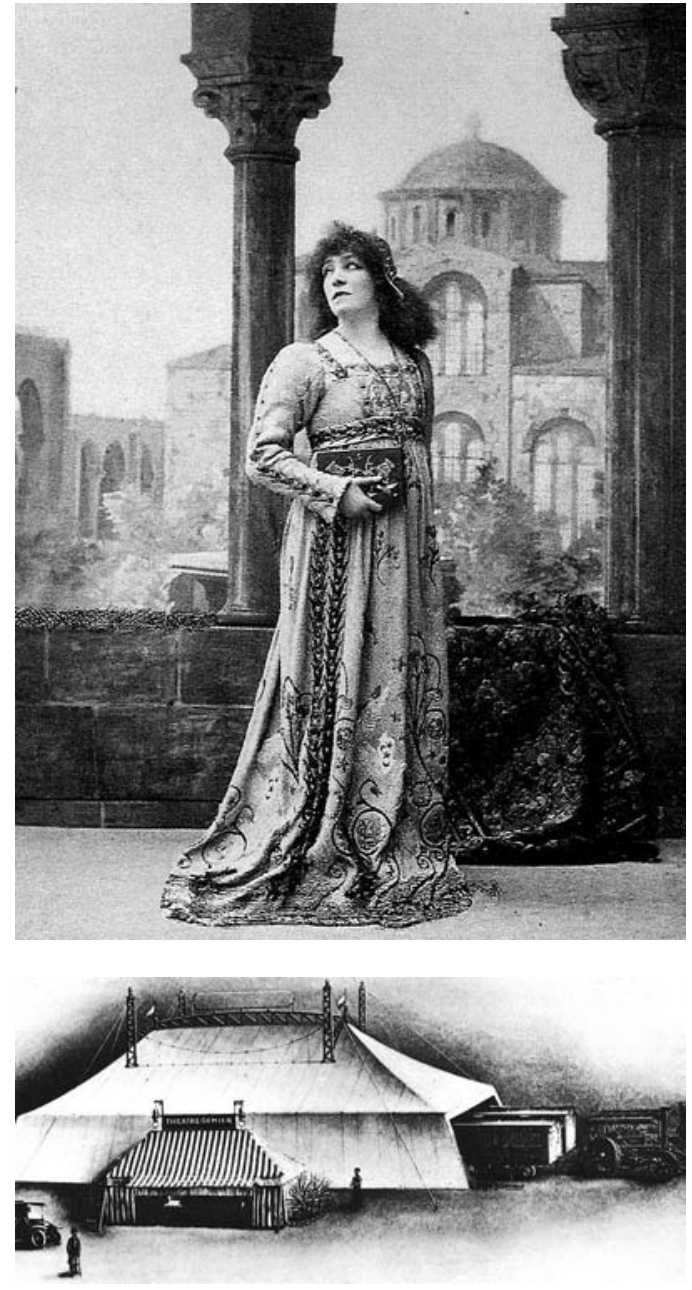

- 0 teatro privado, quase exclusivamente parisiense;

- A formação;

- 0 apoio aos autores e à escrita dramática:

- As actividades internacionais;

- A acção educativa.

0 Estado e as Regiões participam praticamente em percentagens iguais no financiamento público da cultura, destinando cada um cerca de 5.800 milhões de euros. Metade da verba do Estado vem do Ministério da Cultura, a outra metade de outros ministérios, nomeadamente do Ministério da Educação e do Ministério dos Negócios Estrangeiros.

A contribuição orçamental total do Ministério da Cultura, 2.573 milhões de euros, representa pela primeira vez 1\% do orçamento geral do Estado; o orçamento destinado às artes do espectáculo (teatro, música, dança, artes de rua e circo) é de 663,3 milhões de euros, ou seja cerca de $25,8 \%$ do orçamento do ministério.

Quanto às regiões, a França está empenhada num movimento de descentralização política, administrativa e cultural. Um número considerável de câmaras municipais, departamentos e regiões dispõem já de instrumentos

culturais dirigidos por profissionais e adoptam uma política cultural independente, muitas vezes esclarecida, e que, no sector do teatro, apoia companhias, festivais e escolas para a formação de actores. 0 co-financiamento por parte do Estado e das Autarquias Locais (as câmaras municipais em primeiro lugar), dos centros dramáticos e, sobretudo, das cenas nacionais, tornou-se uma regra geral, e o fenómeno está a consolidar-se.

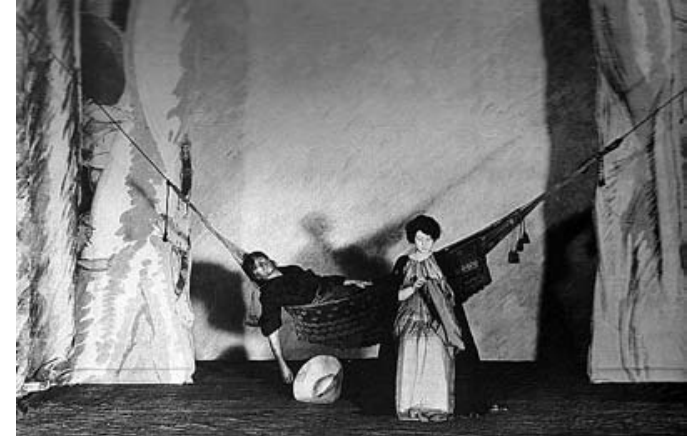

Sarah Bernhardt em Ângelo, tirano de Pádua de Vitor Hugo, fot. Nadar. A troca, de Paul Claudel, enc. Jacques Copeau, Teatro Vieux Colombier, 1914 (Charles Dullin e Maria Kolff), fot. X. D.R. (Photeb.).

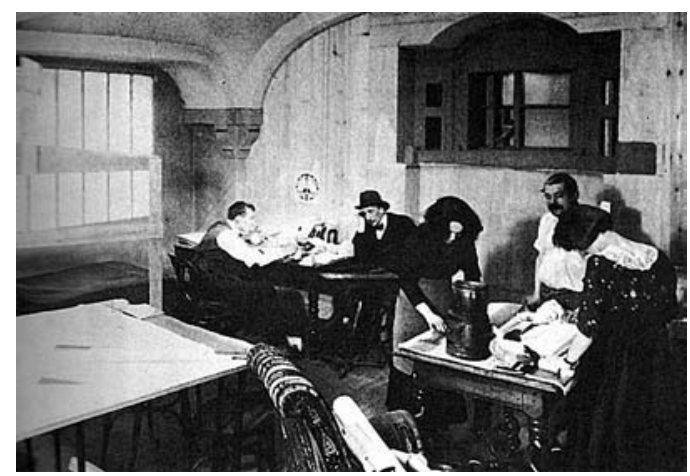

Louis Jouvet (à esquerda de perfil) e Jacques Copeau (de frente), no atelier de cenários do Teatro Vieux Colombier, 1917, fot. X.D.R. (Photeb).

No que diz respeito ao financiamento privado, ao mecenato e aos patrocínios, eles têm uma incidência marginal e, em rigor, irrelevante na vida teatral francesa, excepção feita a algumas grandes instituições, nomeadamente alguns grandes festivais.

\section{Os teatros nacionais}

Os teatros nacionais são cinco. Quatro estão sediados em Paris: a Comédie Française (1680), o L' Odéon (1968), hoje Théâtre de l'Europe, o de Chaillot (1968) e o la Colline (1987). 0 Teatro Nacional de Estrasburgo é, desde 1972, o único implantado numa região.

\section{Os centros dramáticos}

Os centros dramáticos são instituições de criação e difusão teatral constituidas por iniciativa do Estado a seguir à Libertação de 1945, muitas vezes geridos por companhias residentes. Depois do já referido Centre Dramatique de l'Est, criado na Alsácia em 1946, ampliou-se progressivamente até 1960 uma primeira rede de seis centros dramáticos nacionais (Saint-Étienne, 1947; Rennes, 1949; Toulouse, 1949; Aix-en-Provence, 1949; Turcoing, 1960). Em 2003 esta rede nacional contava com 40 unidades: 32 "centros dramáticos nacionais" (CDN), dois deles vocacionados para o teatro para a infância e juventude, e 8 "centros dramáticos regionais" (CDR).

\section{As cenas nacionais}

Instituições multidisciplinares de difusão, por vezes de coprodução artística (na sua grande maioria no sector do teatro, mas também no da dança e da música contemporânea), as "cenas nacionais" são as herdeiras directas das antigas "casas da cultura" criadas a partir de 1961 por iniciativa de André Malraux, e dos "centros de acção cultural e de desenvolvimento cultural" que surgiram na sua esteira. As cenas nacionais constituem, em 2003, uma rede nacional de setenta unidades localizadas no pais inteiro (algumas em Paris, 10 nos arredores parisienses, 61
0 teatro itinerante de Gémier (os carros à direita serviam de camarins aos actores), fot. Michel Didier. 
nas regiões, e têm constituído, nos últimos quarenta anos, os instrumentos privilegiados de uma política de desenvolvimento cultural do território.

\section{As companhias independentes}

$A$ actividade teatral em França não se encontra regulada por nenhuma lei do espectáculo, nem por nenhum regime de carteira profissional. Apenas uma obrigação: a obtenção de uma "autorização de empresário de espectáculos", criada pelos despachos de 1945, dimanados do Ministério da Cultura. É assim que mais de 1200 companhias dramáticas se declaram profissionais. Elas são organizadas em associações ou em sociedades (sociedades de responsabilidade limitada ou sociedades anónimas), que podem assumir a forma de sociedade cooperativas.

\section{Espectáculos de circo e artes de rua}

De há uns anos a esta parte está a ser feito um esforço a favor quer das artes de rua, que se inscrevem de forma significativa nas políticas culturais e festivas dos governos regionais, nomeadamente no quadro da política da cidade e dos bairros; quer ainda do circo, especialmente dos grupos mais jovens, muitas vezes próximos do teatro e da dança, que têm contribuído para a renovação artística desta arte popular.

\section{Os intermitentes do espectáculo}

Chamamos "intermitentes do espectáculo" aos artistas (actores, encenadores, bailarinos, coreógrafos, artistas de circo...), bem como aos técnicos do teatro, audiovisual e cinema que passam por vários empregadores e ficam sujeitos a períodos de desemprego. A indemnização relativa a estes períodos é assegurada pelo regime geral do subsídio de desemprego. Porém, em 2003, uma disposição mais restritiva originou um movimento de protesto, que levou à anulação de numerosos festivais (entre eles, o Festival de Avignon).

De momento um "fundo transitório", assegurado pelo Estado, permite assumir provisoriamente a indemnização aos que não estão nas condições exigidas pela nova disposição, aguardando-se uma renogociação específica para o sector.

\section{A difusão}

Um dos problemas do teatro francês, nomeadamente das companhias independentes, é o da exploração e da difusão insuficientes dos espectáculos. A fim de favorecer a sua circulação, o Ministério da Cultura criou, em 1975, um Gabinete Nacional de Difusão Artística (Office Nacional de Difusion Artistique: ONDA), encarregado de apoiar as itinerâncias, nacionais ou inter-regionais, dos espectáculos teatrais e coreográficos mais inovadores, através de um sistema de garantia parcial de défice permitido aos organizadores, em particular às estruturas menos financiadas. Progressivamente, ao ONDA foi confiada uma missão de ajuda e aconselhamento para a difusão em França dos espectáculos estrangeiros, nomeadamente europeus. A fim de favorecer esta itinerância, o ONDA anima regularmente, em todo o território nacional, reuniões inter-regionais de troca de informações e de cooperação entre estruturas organizadoras, no âmbito de Grupos Regionais de Acção Cultural (GRAC).

\section{0 apoio aos espaços}

Como complemento aos centros dramáticos e às cenas nacionais, o ministério concede o seu apoio, na base da qualidade da sua programação ou da especificidade do seu projecto artístico, a um certo número de teatros. A Direcção da Música, da Dança, do Teatro e do Espectáculo (Direction de la Musique, de la Danse, du Théâtre et des Spectacles: DMDTS) mantém, desde 1999, um programa de "cenas convencionadas" que se apoiam em espaços já existentes, muitas vezes municipais, de criação e difusão, relativamente às quais o Estado deseja acompanhar total ou parcialmente o seu projecto artístico, nomeadamente no que diz respeito ao compromisso com a criação contemporânea (teatro, dança e música) e à política de alargamento do público.

\section{Os festivais}

Entre várias dezenas de manifestações, destacam-se os dois festivais mais importantes: o Festival de Avignon e o Festival de Outono de Paris.

Há ainda uma dezena de festivais de dimensão média, como o Festival internacional das Francofonias, em Limoges, o "Paris quartier d'été" ou o "Printemps des comédiens" de Montpellier, e outros temáticos, como os festivais de Charleville-Mézières para as marionetas, de Aurillac para as artes de rua, de Périgueux para a mímica, de Grenoble para o teatro europeu ou de Bayonne para o teatro ibérico e latino-americano.

Citem-se ainda os encontros consagrados à descoberta de jovens talentos, como "Turbulence" em Estrasburgo ou "Rencontres en mai" em Dijon; bem como os vários encontros organizados pelas cenas nacionais, pelos centros dramáticos ou por determinadas companhias: Créteil ("Exit"), Mauberge ("Via"), Annecy/Chambéry ("La banane bleue"), Rennes ("Mettre en scène"), Poitier ("Jeux d'écritures"), Nantes ("Fin de siècle" e "Trafics"), Nancy ("Passage"), Le Havre ("Printemps du volcan"), Fort-de-France ("Rencontres caribéennes de théâtre"), Douai ("Les météores"), Tours ("Acteurs acteurs"), etc.

\section{Os organismos especializados}

Com o apoio do Ministério da Cultura foram criados vários organismos especializados, que funcionam ao mesmo tempo como espaços que oferecem recursos e lugares de encontro para profissionais e investigadores, bem como instrumentos de promoção nacional e internacional: um Centro Nacional de Teatro, que anima em particular um centro de informação e de documentação; o Instituto Internacional da Marioneta, em Charleville-Mézière, e a associação "Themaa", também para a arte da marioneta; o Centro Nacional das Artes do Circo, em Châlons-en-Champagne; o Centro Nacional das Escritas do Espectáculo, de Villeneuve-lez-Avignon; um 




Centro Internacional da Tradução de Teatro, Maison Antoine Vitez; e a Associação "Hors le murs", encarregada da promoção das artes de rua e do circo.

\section{A acção internacional}

A responsabilidade principal pela presença artística francesa no estrangeiro cabe aos Negócios Estrangeiros e ao seu "braço secular", a Associação Francesa de Acção Artística (AFAA). Ao Ministério da Cultura compete apoiar em particular o acolhimento das culturas estrangeiras em França, nomeadamente por intermédio do seu departamento dos assuntos internacionais.

A acção internacional da DMDTS no campo do teatro traduz-se especialmente no apoio que dá a organismos como o Teatro Nacional de L'Odéon / Théâtre de l'Europe, a Casa das culturas do mundo, o Teatro Internacional da lingua francesa, o Festival das Francofonias, o Instituto Nacional da Marioneta ou a Maison Antoine Vitez.

A DMDTS apoia também iniciativas especificas, como o projecto Thierry Salmon / a nova École des Maîtres, a academia internacional itinerante de formação de jovens actores, em que participam a Itália, a França, a comunidade francesa da Bélgica, Portugal e a Espanha.

\section{0 teatro privado}

Mesmo não usufruindo de financiamentos directos, os 47 teatros privados (46 em Paris e 1 em Lyon) beneficiam, todavia, de apoios públicos, por intermédio da Associação de Apoio ao Teatro Privado, mais comummente conhecida como "Fonds de soutien", sob a forma de apoio à exploração e à criação de espectáculos, bem como aos equipamentos ou à reabertura de salas.

\section{Os autores}

O Ministério da Cultura lançou medidas e estruturas especificas a favor dos dramaturgos contemporâneos de língua francesa: um sistema de encomendas aos autores; o apoio à criação de textos dramáticos; 0 apoio ao Centro Nacional de Escritas do Espectáculo, de Villeneuve-lezAvignon, que tem por missão favorecer o desenvolvimento e a promoção das escritas para teatro, organizando programas de residência para autores, leituras públicas e leituras encenadas.
Cite-se ainda a obrigação recente dos centros dramáticos, inscrita no contrato de descentralização desde 1995, de nomear um leitor encarregado de examinar os textos recebidos e de encenar, durante o contrato trienal do seu director, três peças de um dramaturgo vivo de língua francesa e que não coincida com o director desse centro.

\section{A formação}

No que diz respeito à formação do actor, são oito as escolas que ministram uma formação profissional inicial: 0 Conservatório Nacional Superior de Arte Dramática (CNSAD), em Paris; a Escola Nacional Superior das Artes e Técnicas do Teatro (ENSATT), em Lyon, que depende do Ministério da Educação; dois conservatórios nacionais fora de Paris (Bordéus e Montpellier), que possuem um departamento de arte dramática; quatro escolas ligadas, respectivamente, ao Teatro Nacional da Bretanha, ao Teatro Nacional de Chaillot, ao CDN de Saint-Etienne e à Escola Regional de Actores de Cannes.

Dois organismos ministram uma formação especializada: a Escola Nacional Superior das Artes da Marioneta, de Charleville-Mézières e o Centro Nacional das Artes do Circo, de Châlons-en-Champagne.

\section{A acção educativa}

Desde 1985 o Ministério da Cultura desenvolve um programa de "ensino especializado de teatro" em determinados estabelecimentos do segundo ciclo do ensino secundário (120 liceus neste momento).

\section{0 público do teatro}

No âmbito dos estudos realizados todos os sete anos pelo Ministério da Cultura, o último de que temos notícias é de 1997 e conclui que, em cada 100 franceses, de 15 anos ou mais, 16 tinham ido ao teatro pelo menos uma vez nos últimos doze meses (eram 14 em 1989, 12 em 1981, 10 em 1973). A progressão é regular, mas não implica uma redução significativa das diferenças entre niveis sociais. Acrescentese ainda que em 1997, 43 franceses em cada 100 (contra 55 em 1989) nunca tinham assistido a uma representação teatral. Apesar dos esforços realizados, é necessário continuar a corrigir as assimetrias existentes entre Paris e as regiões, em prol da democratização da cultura e da luta contra as desigualdades sociais e culturais. 0 teatro não tem as armas decisivas para esse combate, ainda que, fiel à sua vocação milenar, ocupe um lugar de destaque na arte que une todos os cidadãos.

* Este artigo é uma versão abreviada de uma conferência proferida na Faculdade de Letras de Lisboa, no âmbito do Mestrado em Estudos de Teatro, em Março de 2004.

Tradução de Sebastiana Fadda

\section{Da esquerda para a direita Jeanne Moreau, Gérard Philipe e Jean Vauthier quando da criação d'A nova mandrágora, TNP, 1952, \\ fot. Lipnitzki.}

